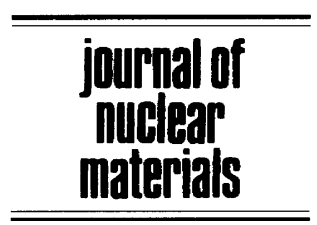

www.elsevier.com/locate/jnucmat

\title{
CDX-U operation with a large area liquid lithium limiter
}

\author{
R. Majeski ${ }^{\text {a,* }}$, M. Boaz ${ }^{\text {a }}$, D. Hoffman ${ }^{\text {a }}$, B. Jones ${ }^{\text {a }}$, R. Kaita ${ }^{\text {a }}$, H. Kugel ${ }^{\text {a }}$, \\ T. Munsat ${ }^{\text {a }}$ J. Spaleta ${ }^{\text {a, }, ~ V . ~ S o u k h a n o v s k i i ~}{ }^{\text {a }}$, J. Timberlake ${ }^{\text {a }}$, L. Zakharov ${ }^{\text {a }}$, \\ G. Antar ${ }^{\mathrm{b}}$, R. Doerner ${ }^{\mathrm{b}}$, S. Luckhardt ${ }^{\mathrm{b}}$, R.W. Conn ${ }^{\mathrm{b}}$, M. Finkenthal ${ }^{\mathrm{c}}$, \\ D. Stutman ${ }^{\mathrm{c}}$, R. Maingi ${ }^{\mathrm{d}}$, M. Ulrickson ${ }^{\mathrm{e}}$ \\ a Princeton Plasma Physics Laboratory, P.O. Box 451 Princeton, NJ 08543, USA \\ ${ }^{\mathrm{b}}$ University of California at San Diego, San Diego, CA, USA \\ ${ }^{\mathrm{c}}$ Johns Hopkins University, Baltimore, MD, USA \\ d Oak Ridge National Laboratory, Oak Ridge, TN, USA \\ e Sandia National Laboratory, Albuquerque, NM, USA
}

\begin{abstract}
The current drive experiment-upgrade (CDX-U) at the Princeton Plasma Physics Laboratory has begun experiments with a fully toroidal liquid lithium limiter. CDX-U is a compact $\left(R=34 \mathrm{~cm}, a=22 \mathrm{~cm}, B_{\text {toroidal }}=2 \mathrm{kG}, I_{\mathrm{P}}=100 \mathrm{kA}\right.$, $\left.T_{\mathrm{e}}(0) \sim 100 \mathrm{eV}, n_{\mathrm{e}}(0) \sim 5 \times 10^{19} \mathrm{~m}^{-3}\right)$ short-pulse $(<25 \mathrm{~ms})$ spherical torus with extensive diagnostics. The limiter, which consists of a shallow circular stainless steel tray of radius $34 \mathrm{~cm}$ and width $10 \mathrm{~cm}$, can be filled with lithium to a depth of a few millimeters, and forms the lower limiting surface for the discharge. Heating elements beneath the tray are used to liquefy the lithium prior to the experiment. Surface coatings are evident on part of the lithium. Despite the surface coatings, tokamak discharges operated in contact with the lithium-filled tray show evidence of reduced impurities and recycling. The reduction in recycling is largest when the lithium is liquefied.
\end{abstract}

(C) 2003 Elsevier Science B.V. All rights reserved.

PACS: 52.40.Hf; 52.55.Fa; 28.52.Fa

Keywords: Lithium; Tokamak; Limiter

\section{Introduction}

The use of flowing liquid metals, and in particular liquid lithium, as plasma-facing components (PFCs) in a tokamak reactor offers many potential benefits over conventional solid PFCs. These include high heat removal capability, self-healing, pumping of hydrogenics (including tritium, to limit the inventory captured in fixed PFCs), a potential for pumping helium ash, and the possibility of reactor operation at higher plasma beta, provided that the liquid metal is close to the last closed flux surface and flowing at a sufficiently high

\footnotetext{
${ }^{*}$ Corresponding author. Fax: +1-609 2432418.

E-mail address: rmajeski@pppl.gov (R. Majeski).
}

velocity [1]. Experiments to test the use of liquid lithium as a PFC were first performed on the T11-M tokamak, [2-4] and are presently underway at the PISCES-B divertor simulator facility [5] and the current drive experiment-upgrade (CDX-U) at the Princeton Plasma Physics Laboratory. The CDX-U experiments are the first to focus on large-area liquid metal limiters [6]. Previous experiments with lithium systems in CDX-U utilized a rail limiter [5,7] similar in size to the T11-M system, with a lithium-wet mesh surface with an area of approximately $300 \mathrm{~cm}^{2}$. The area of the limiter wet by the plasma was approximately $40 \mathrm{~cm}^{2}$. The rail limiter experiments demonstrated that liquid lithium could be successfully and safely employed as a PFC in CDX-U, with no deleterious effects on the discharge. The ejection of small scale lithium droplets from the limiter due to 
MHD forces was observed, but the effect of these droplets on the discharge was minimal [7].

\section{The CDX-U liquid lithium limiter}

Following these tests, a circular tray $34 \mathrm{~cm}$ in radius, $10 \mathrm{~cm}$ wide, and $0.5 \mathrm{~cm}$ deep was mounted on the bottom of the CDX-U vacuum vessel and loaded with lithium. The lithium area was therefore increased to a maximum of $2000 \mathrm{~cm}^{2}$. The area wet by the plasma varies, but is on the order of several hundred $\mathrm{cm}^{2}$. Fig. 1 is a photograph of the interior of CDX-U with the tray limiter installed.

The tray limiter is fitted with resistive disk heaters clamped to the lower surface, which are capable of heating the tray to $400{ }^{\circ} \mathrm{C}$ (lithium melts at $180^{\circ} \mathrm{C}$ ). The tray is constructed in two halves, with a single toroidal electrical break. The two halves of the tray are connected to separate high current vacuum feedthroughs, so that the tray may be electrically grounded or floated with respect to the vacuum vessel. During operation of CDX-U, the tray serves as a fully toroidal limiter for the discharge, and hence forms a principal PFC for CDX-U.

The tray has been loaded with approximately 200 $\mathrm{cm}^{3}$ of solid lithium. The loading operations were performed under vacuum or dry argon to minimize oxidation of the lithium surface. However, the tray was not uniformly wet and filled by the lithium. Although the reasons for the observed non-uniform wetting are not entirely clear, we note that a turbopump failure occurred after the tray was installed, but prior to loading lithium onto the tray. As a result, hydrocarbons were admitted to the vacuum vessel and may have formed a coating on the tray. Also, recent experiments at UCSD indicate that higher temperatures (in excess of $500{ }^{\circ} \mathrm{C}$ ) are desirable for the initial wetting process [8]. For the experiments

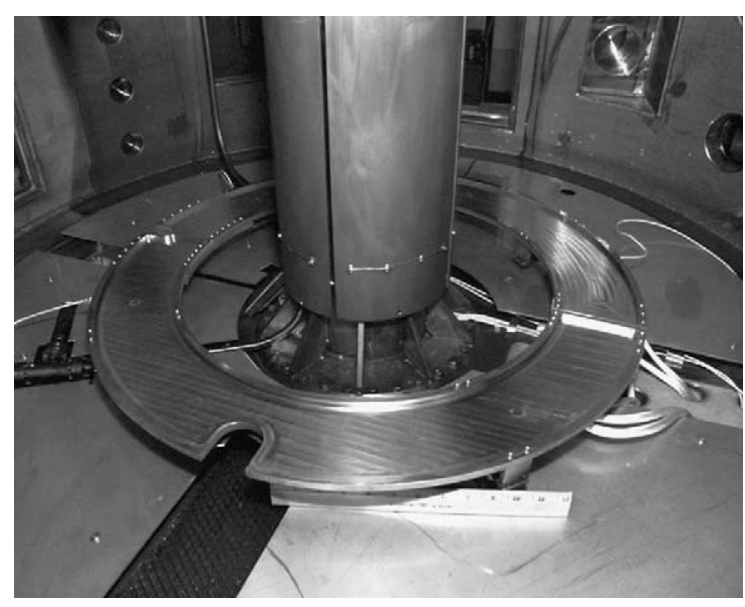

Fig. 1. Photograph of the interior of CDX-U following installation of the tray limiter. described here approximately $50 \%$ of the tray was covered with lithium to a maximum depth of approximately $5 \mathrm{~mm}$. The lithium also exhibited a surface coating of oxide or hydroxide, which was partially removed by glow discharge cleaning.

\section{Results of plasma operation with the liquid lithium limiter}

During initial operation of tokamak discharges with the lithium tray limiter, numerous unipolar arcs to the surface of the lithium fill were observed with a fast (10000 frames per second) camera in the discharge scrape-off layer (SOL). The incidence of arcing did not substantially change when the lithium was liquefied. These arcs ejected a lithium particulate, with a scale size of $1 \mathrm{~mm}$ or less, radially outward, which corresponds to the $J_{\text {arc }} \times B_{\text {toroidal }}$ direction. This particulate was deposited on the lower vessel heat shield (visible as semicircular plates in Fig. 1), and has had no effect on plasma operations. The incidence of unipolar arcing dropped as plasma operations continued, an indication that the lithium surface was being discharge cleaned. Unipolar arcing has not been observed on clean lithium surfaces which lack an insulating oxide coating.

Even with a partially filled tray which is subject to surface coatings, changes in the plasma edge and global effects on plasma performance have been observed. Fig. 2 is a plot of the peak plasma current obtained versus lineaveraged density for plasmas limited by the bare stainless steel tray, the room-temperature (solid) lithium-filled tray, and the liquid lithium-filled tray at $250{ }^{\circ} \mathrm{C}$. In each case the tray or fill surface was conditioned for several hours by argon glow discharge cleaning before tokamak discharges commenced. Higher plasma current is

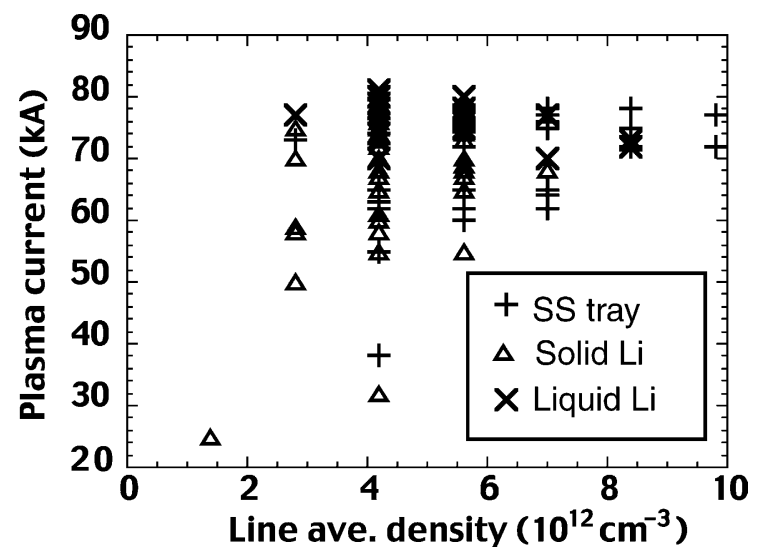

Fig. 2. Plasma current - line-averaged density operating space for CDX-U with an empty stainless steel tray limiter, a solid lithium fill, and a liquid lithium fill. The horizontal grouping of the density data is due to a binning algorithm. 
indicative of a hotter, cleaner discharge, since CDX-U operates with fixed loop voltage rather than plasma current feedback. It is clear that slightly higher current discharges were obtained with liquid lithium in the tray. This change in global performance is underscored by the observation that little or no conditioning is required to reach peak operating current in CDX-U when the lithium in the tray is liquefied. Prior to the installation of the toroidal lithium limiter, several hours of operation (involving dozens of discharges) at lower current were required before peak operating current was obtained.

Reduced impurity levels, particularly of oxygen, improve discharge performance. Spectroscopy indicated significant changes in the edge impurities local to the tray. Fig. 3 shows the effect of solid and liquid lithium limiting surfaces on the oxygen impurity in the plasma. There is a good correlation between higher plasma current and reduced oxygen levels. Note the segregation of the data; nearly all the discharges with a solid lithium limiter show lower oxygen than discharges which are limited by a bare stainless steel tray. Discharges limited by liquid lithium show further reductions.

One indication of hydrogen pumping by the liquid lithium during these experiments (CDX-U uses deuterium as a working gas) is that the plasma density obtained with liquid lithium in the tray was lower than for solid lithium or the bare stainless steel tray, for similar gas puffing rates. Operation with liquid lithium also reduced recycling. A comparison between $D_{\alpha}$ emission from the SOL at the tray surface for operation with solid and liquid lithium is shown in Fig. 4. Virtually all the discharges with liquid lithium in the tray show reduced $D_{\alpha}$ emission compared to the discharges with solid lithium. This result agrees with previously obtained data indicating that the recycling coefficient for hydrogenic species on liquid lithium is very low [9]. The high mobility of hydrogenic species in liquid lithium allows

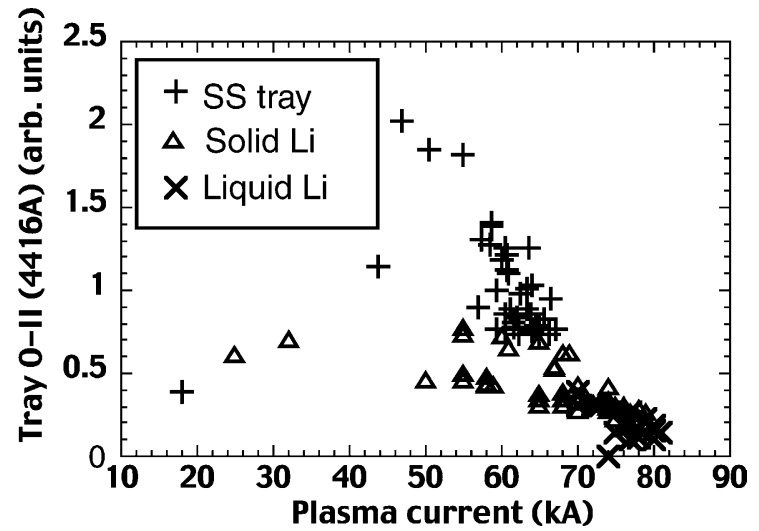

Fig. 3. Oxygen II emission at the surface of the tray, for discharges limited by the empty tray, a solid lithium fill, and a liquid lithium fill.

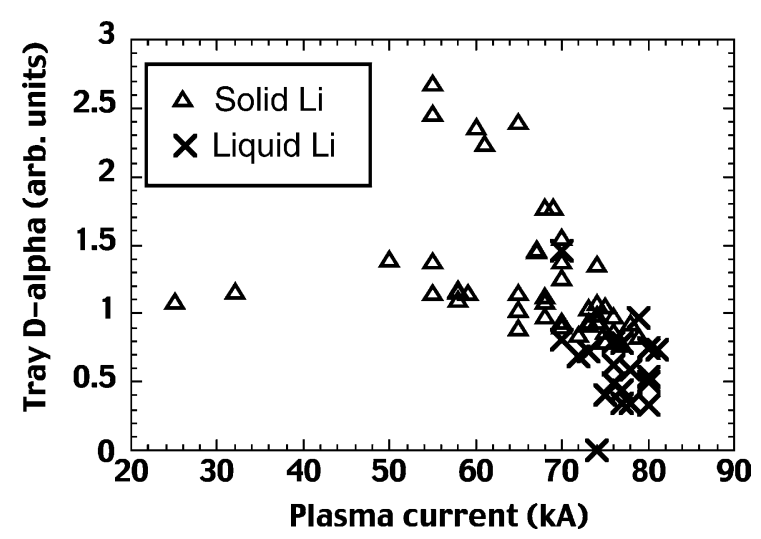

Fig. 4. $D_{\alpha}$ emission at the lithium-filled tray, for solid and liquid lithium limited discharges.

deuterium to diffuse out of the ion implantation zone, which only extends a few tens of Angstroms from the surface. It should also be stressed that while the viewed area represented in Fig. 4 is primarily covered with lithium, parts of the stainless steel tray are still exposed and some of the lithium is oxide coated. Therefore, the residual recycling seen in the data with liquid lithium may be due to viewing of a small bare area on the tray, or a coated area on the lithium fill. The $D_{\alpha}$ emission data also shows the same correlation with plasma current evidenced by the oxygen emission data.

In Fig. 5 we display the lithium emission as a function of plasma current. It can be seen that while lithium light is significantly higher in the liquid case, as compared to the solid, there is no negative correlation with plasma performance.

\section{Discussion}

Reduced recycling is one hallmark of the enhanced performance modes observed in TFTR through the use

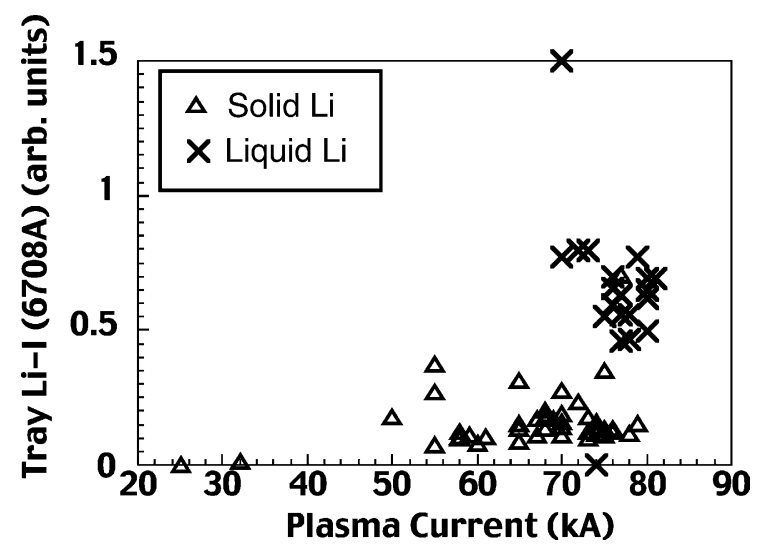

Fig. 5. Lithium I emission at the lithium-filled tray, for solid and liquid lithium limited discharges. 
of lithium pellets or coatings [10,11]. Global recycling data is not available for CDX-U, but a comparison of the area of the tray to the area of the centerstack (visible in Fig. 1 as the cylindrical column in the center of the device) and other room-temperature surfaces which contact the plasma indicates that the tray represents less than $40 \%$ of the total area of PFCs in CDX-U. In light of the limited area of the tray and the incomplete coverage of the tray by lithium, the tray cannot produce more than a $20 \%$ reduction in total recycling. It is therefore likely that the enhanced performance seen with liquid lithium PFCs in CDX-U is due to a reduction in oxygen impurities, rather than recycling.

Efforts were made to eliminate the effects of possible wall coatings in these experiments. During the filling and wetting process, and for all data taken until, and including, that displayed in Figs. 2-5, the tray temperature was limited to less than $325^{\circ} \mathrm{C}$, at which temperature the equilibrium vapor pressure of lithium is negligible. No reduction in optical transmission of any of the vacuum vessel windows was observed prior to or during the experiments. Furthermore, for the data displayed in Figs. $2-5$, the experiments with liquid lithium were performed first. The lithium was then allowed to resolidify, and the data with solid lithium in the tray was taken. Therefore, wall coatings produced during operation with liquid lithium would have been present during the solid lithium experiments as well. Finally, OII and $D_{\alpha}$ emission at the centerstack was also monitored. Although this data shows the same general drop with plasma current as the data shown in Figs. 3 and 4, the centerstack OII and $D_{\alpha}$ emission data taken with solid and liquid lithium overlay. There is no additional reduction in centerstack emission when the lithium is liquefied. Hence the reduction in oxygen and recycling during liquid lithium operation shown in Figs. 3 and 4 appears to be due to the use of liquid lithium as a PFC, rather than the effect of solid wall coatings evolved when the lithium is heated.

The CDX-U experiments indicated that a fresh coating of solid lithium does not necessarily eliminate recycling. After the data shown in Figs. 2-5 was taken, operation of the tray at a significantly higher (but undiagnosed) temperature resulted in evaporation of part of the tray fill and a lithium coating over the vacuum vessel and centerstack. Data taken immediately after the coating was applied indicate that recycling on the cold lithium-coated centerstack was comparable to or slightly higher than recycling on the uncoated centerstack. This is understandable, since a typical CDX-U discharge is many (20-50) particle confinement times in duration, and the edge electron temperature is typically $10-20 \mathrm{eV}$, which results in a modest ion implantation range in PFCs. Hence a solid lithium coating on the centerstack should saturate with deuterium in the course of a single discharge. Since the mobility of hydrogen in solid lithium is low, solid coatings should not be effective at re- ducing recycling in subsequent discharges. However, the solid lithium coating on the vessel walls was very effective at eliminating water, and correspondingly the oxygen content of the discharge was reduced.

\section{Conclusions}

To summarize, discharges struck on the lithium-filled limiter outperform discharges struck on the bare stainless steel tray. Furthermore, discharges struck on a liquid lithium-filled limiter outperform those limited either by the bare stainless steel tray or by the solid lithiumfilled tray. This effect is observed despite the fact that the tray is only partially filled with lithium, and is partly coated with oxide and hydroxide layers.

The enhancement in performance is correlated with a strong reduction in both oxygen impurities and recycling at the lithium-filled limiter tray. The data on oxygen and $D_{\alpha}$ emission reveal that nearly all the discharges limited on liquid lithium show lower emissions than nearly all the discharges limited on solid lithium. Thus liquid lithium is much more effective at removing oxygen and eliminating recycling than an equivalent area of solid lithium. Solid lithium coatings do not reduce recycling in CDX-U.

\section{Future work}

Upcoming experiments on CDX-U will utilize new filling techniques for the tray, developed in collaboration with the PISCES-B group at the University of California at San Diego, and new radio-frequency discharge cleaning techniques. The objective is to obtain full coverage of the tray with a uniform fill of lithium, and to develop improved techniques for removing surface oxide coatings. During 2003 a recirculating liquid lithium limiter is planned for installation in CDX-U.

\section{Acknowledgements}

We acknowledge a wealth of useful information and advice from our US colleagues in the ALPS and APEX programs, and from S. Mirnov of the T11-M group at Troitsk. This work was supported by USDOE contract no. DE-AC02-76-CHO3073.

\section{References}

[1] S.I. Krashneninnikov, L.E. Zakharov, G.V. Pereverzev, UCSD Report UCSD-ENG-091, 2002, Phys. Plasmas, submitted for publication. 
[2] V.A. Evitkhin et al., Proceedings of the 17th IAEA Fusion Energy Conference, Yokohama, Japan 19-24 October 1998, paper IAEA-CSP-1/P, vol. 4, p. 1309.

[3] V.A. Evtikhin et al., Proceedings of the 18th IAEA Fusion Energy Conference, Sorrento, Italy 4-10 October 2000, paper IAEA-CN-77/EXP4/21.

[4] V.A. Evtikhin et al., Fus. Eng. Des. 56-57 (2001) 363.

[5] S. Luckhardt et al., Proceedings of the 19th IEEE/NPSS Symposium on Fusion Engineering, Atlantic City, NJ, 2002.
[6] R. Kaita et al., 6th Int. Symposium on Fusion Nuclear Technology, San Diego, CA, 2002, Fus. Eng. Des., in press.

[7] G. Antar et al., Fus. Eng. Des. 60 (2002) 157

[8] M. Baldwin, personal communication.

[9] M. Baldwin, S.C. Luckhardt, R.W. Conn, Nucl. Fusion, in press.

[10] D.K. Mansfield et al., Phys. Plasmas 3 (1997) 1892.

[11] D.K. Mansfield et al., PPPL Report PPPL-3526, 2002, Phys. Plasmas, submitted for publication. 